\title{
EL INKA Y EL PODER COMO PROBLEMAS DE LA ARQUEOLOGÍA DEL NORTE GRANDE DE CHILE
}

\author{
INKA AND POWER PROBLEMS ON \\ THE ARCHAEOLOGY OF NORTHERN CHILE
}

\author{
Mauricio Uribe Rodríguez*
}

\begin{abstract}
Los avances en la historia cultural de las poblaciones circumpuneñas del desierto de Atacama, en especial aquellas de los períodos Intermedio Tardío (950-1.450 d.C.) y Tardío (1.450-1.550 d.C.), han permitido profundizar y problematizar la expansión del Imperio Incaico. A la luz de sus diversas evidencias materiales y paralelo al surgimiento de críticas a los modelos e interpretaciones en boga, se ha generado la necesidad de innovar en el entendimiento de las relaciones entre el Tawantinsuyo y las poblaciones locales del Norte Grande de Chile, a partir de un caso concreto como aquellas de Atacama y centrándonos en el concepto de "ideología". Para ello, recurrimos a las propuestas teóricas y metodológicas de las corrientes estructuralistas, marxistas y simbólicas de la arqueología contemporánea, las cuales contexualizamos en el estudio de San Pedro de Atacama.
\end{abstract}

Palabras claves: San Pedro de Atacama, Inka, ideología, arqueología postprocesual.

The advance in the cultural history of circumpuna peoples at the Atacama Desert, during Late Intermediate (A.D. 950-1450) and Late periods (A.D. 1450-1550), have allowed us to develop new ideas about the expansion in of the Inka Empire. Based on different cultural materials and new critical views about current model and interpretation, of the relationships between Tawantinsuyo and local peoples of Northern Chile. In this context we focuss on the concept of "ideology", based on the theory and methodology of structuralism, marxism and symbolic of postprocessual archaeology.

Key words: San Pedro de Atacama, Inka, ideology, postprocessual archaeology.

Los avances de la historia cultural de las poblaciones circumpuneñas del desierto de Atacama, en especial aquellas de las cuencas del río Loa y San Pedro de Atacama durante los períodos Intermedio Tardío y Tardío (950-1.550 d.C.), han permitido profundizar y problematizar acerca de la expansión del Imperio Incaico en este territorio, así como reflexionar acerca de la conformación del Tawantinsuyo. En primer lugar, hoy es innegable la existencia de abundantes restos de la presencia del Inka en Atacama, los que se distribuyen diferencialmente a través de tambos, canchas, collcas, usnos, santuarios de altura, aríbalos, tejidos, miniaturas y adornos de metal y arte rupestre. Por lo tanto, esta presencia, además de referir a cierto control de la producción económica, artefactual y las tecnologías asociadas a ellos, insinúa una significativa intervención del patrón de asentamiento local y de la sociedad misma. Pero, sin una "violencia" manifiesta.

A la luz de estas diversas evidencias materiales y paralelo al surgimiento de las críticas a los modelos e interpretaciones en boga (Uribe 19992000), se ha generado la necesidad de reflexionar sobre las relaciones entre el Imperio y las poblaciones del Norte Grande de Chile, a partir de un caso concreto como el de Atacama, apoyados en nuestros trabajos previos y discutiendo conceptos derivados de esta realidad arqueológica. Por lo tanto, en esta oportunidad se evalúan ciertas evidencias incaicas y los distintos modelos e interpretaciones al respecto, intentando contribuir al debate en torno de la expansión, dominación e integración de Atacama al Tawantinsuyo, centrándonos en el concepto de "ideología". Para ello, recurrimos a las propuestas de las corrientes estructuralistas, marxistas y simbólicas de la arqueología contemporánea, las cuales contexualizamos en el estudio de San Pedro de Atacama (Figura 1).

\section{Ideología en Arqueología}

Con el tiempo se ha consolidado una reacción de la arqueología a las concepciones mecánicas y

* Departamento de Antropología, Universidad de Chile. Ignacio Carrera Pinto 1045, Ñuñoa, Santiago. mur@uchile.cl 


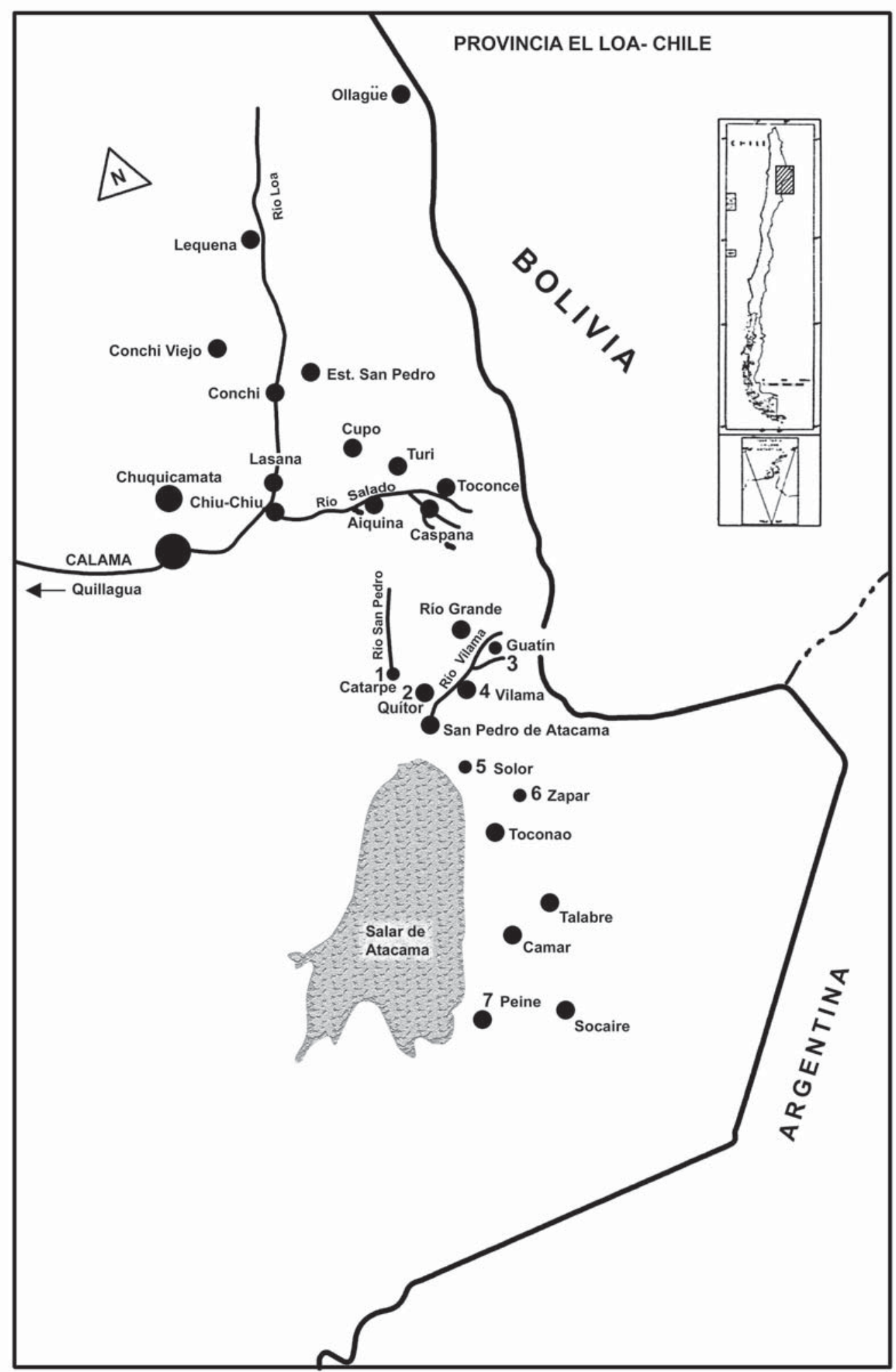

Figura 1. Región atacameña y principales localidades del río Loa y San Pedro de Atacama mencionadas en el texto (gentileza de Victoria Castro).

Atacameña region and principal location at Loa river and San Pedro de Atacama (courtesy of Victoria Castro). 
reduccionistas del procesualismo, delatando una marcada y sospechosa pasividad de este enfoque frente al estudio del pasado con relación tanto al accionar de las poblaciones pretéritas como de los propios investigadores (Hodder 1994). Dicha reacción, paralelamente, no se ha mantenido en un simple alarde intelectual postmoderno; muy por el contrario, ha invertido de manera sistemática y acorde con la disciplina, en vías teóricas y metodológicas posibles de ser empleadas en la investigación del pasado, con el propósito de llegar a una comprensión más sustantiva de la historia. Un vital aspecto de esto y, en consecuencia, inicial del replanteamiento hecho, es el cambio epistemológico como ontológico de nuestros conceptos disciplinarios.

Al respecto, para Leone (1986) la arqueología crítica, estructural y simbólica juega un papel protagónico en esto. Se trata de tres diferentes enfoques de los datos arqueológicos referidos al significado, la ideología, estructuración y cognición, que operan con los mismos supuestos aún cuando sus análisis no son necesariamente idénticos. Los supuestos mencionados se encuentran basados en la cualidad recursiva o interactiva de la cultura, es decir, se asume que la gente crea, usa, modifica y manipula sus capacidades simbólicas, haciendo y rehaciendo el mundo donde ellos viven. En arqueología, el mayor impacto de lo anterior tiene su efecto en comprender la cultura material como un "instrumento" para crear significado y configurar el mundo. Retomando a Giddens, Leone plantea que se cambia el énfasis desde las consecuencias a las intenciones y motivaciones de la acción humana que reproducen en la práctica las condiciones de su existencia. Y, se entiende a la gente como actores propiamente tales, a los símbolos como fundamentales para la existencia humana y a la cultura material como análogo del lenguaje en su capacidad ordenadora de mundo. Lo anterior conlleva, consiguientemente, a un énfasis en el significado y la interpretación a partir de una multivocalidad de posibilidades.

En este sentido, el tema de la ideología se vuelve significativo, ya que, a diferencia de los materialismos básicos o tradicionales que han definido este concepto de una manera muy vinculada a la religión, aquí la discusión se centra en la interacción entre la vida cotidiana, las relaciones sociales y el pensamiento (Leone 1986). Según la Arqueología Crítica, la ideología es el mecanismo de los sistemas simbólicos que enmascara las contradic- ciones de la sociedad, manejando el conflicto resultante de ello (e.g. los intereses de clase, entre otros), reproduciéndose la sociedad bajo una idea particular. Por lo tanto, el manejo del conocimiento (como la ciencia en nuestro caso) tampoco se halla alejado de ser una representación ideológica, pues las ideas se convierten en vehículos activos a través de la cultura como un saber-poder. Así, conocimiento, pasado y cultura son construcciones sociales activas como plantea el cognitivismo, que no existen fuera de la realidad sociocultural y que, al mismo tiempo, cumplen un papel político concreto. Se entiende, asimismo, que la cultura facilita la realidad social a través de los símbolos, los cuales se vuelven centrales y poderosos en la ordenación del mundo, pues así se racionaliza, disciplina y domina (Foucault 2002). Por lo mismo, los productos derivados de la cultura requieren una interpretación y no sólo su lectura.

Lo anterior, obviamente, resulta opuesto a la idea de cultura que tenía la Nueva Arqueología Procesualista en cuanto reflejo estático, mensurable y explicable de la realidad. Al contrario, ahora se entiende que tales concepciones son contingentes y políticas, lo cual es posible por la dimensión material de la cultura que fija las situaciones, cumpliendo dicha materialidad un papel activo en la conducta social aquí y en el pasado (así como en la del investigador que lo interpreta). Así, el tiempo y el pasado por su connotación de origen y pertenencia, conceptos tan significativos socialmente, no son términos neutros. De hecho, esto toca de manera directa a los arqueólogos, por cuanto no sólo excavamos el pasado, sino que también lo pensamos. Por lo tanto, en toda época se ha invertido en las representaciones de mundo, por ejemplo, del pasado, razón por la que es imperativo en su estudio establecer qué ideas evocan los restos materiales para un mejor acercarmiento a esa realidad social en particular (Gallardo 2004).

\section{El Inka en el Norte Grande de Chile}

A mediados de 1970 en el norte de Chile surgió la conocida discusión si el dominio incaico había sido "directo o indirecto", a partir de la aplicación arqueológica que hizo Llagostera (1976) del modelo del control vertical de Murra (1972). De acuerdo a su propuesta, esta situación se dirimía en términos de que la materialidad que representaba al Inka en los territorios conquistados era más o 
menos abundante, cuánto se atenía ésta al estilo original del Cuzco, en especial a sus patrones cerámicos, y cuáles eran sus vínculos con la ocupación "vertical" del espacio andino. En este sentido, Llagostera planteaba para el Norte Grande la ausencia de una conquista propiamente tal, puesto que sus poblaciones se hallaban insertas dentro de sistemas preincaicos de complementariedad ecológica; cuyas cabeceras o "señoríos" que se encontraban en el altiplano, una vez anexados al imperio, implicaban un dominio de las restantes entidades del norte chileno.

Su argumentación empírica descansaba en la existencia o no de una industria inka local y la presencia de alfarería de origen cuzqueño o inka altiplánico como el conocido tipo Saxámar o Inka Pacajes (Dauelsberg 1959; Munizaga 1957; Pärssinen y Siiriäinnen 1997). De hecho, esta cerámica se señalaba como el indicador diagnóstico del proceso, derivada de situaciones altiplánicas post-Tiwanaku y preincaicas (e.g. Chilpe, Hedionda, Taltape, etc.), asumiendo una directa analogía entre alfarería y población, incluso como "colonias" (Schiappacasse et al. 1989).

No obstante, hasta fines de 1980 esta perspectiva no consideraba la gran concentración de restos incaicos que comenzaron a evidenciarse los años siguientes (Raffino 1981; Uribe 1999-2000). A partir de esto, entonces, se manifiestan claras falencias en los modelos aplicados. Especialmente, porque se establece una analogía demasiado directa, casi étnica, de poblaciones con alfarería, desconociéndose el desarrollo y fortaleza de la cultura local, cuyas diferencias son entendidas en forma muy mecánica como dominio político. Sin embargo, en el desierto de Atacama, junto con mayores logros empíricos sobre este tema, se ha avanzado mucho en la discusión de reduccionismos como éstos.

En Atacama tampoco había existido mayor crítica al modelo. Al contrario, fue reinterpretado con distintos énfasis (e.g. Núñez y Dillehay 1995). Desde los pioneros de la arqueología atacameña como Latcham (1938), se indicaba que estas regiones no habían sido ocupadas por los inkas a excepción de algunos asentamientos a lo largo del camino imperial, concentrándose al sur de San Pedro de Atacama. Al respecto, la cerámica local sólo adoptaba algunas formas y decoración sin cambiar de un modo esencial; se aprovechaban poblados preexistentes como los "pucaras" de Quítor, Catarpe y Turi (Mostny 1949), y se potenciaba algo su producción agrícola (Núñez 1991). Coincidente con lo anterior, se introduce la mencionada perspectiva de Llagostera y como consecuencia de lo mismo, gracias a los estudios del Pucara de Turi, Aldunate (1991) propone que el Inka habría llegado tempranamente a la zona a través de la tradición altiplánica que caracterizaba al curso superior del Loa, notándose su influencia en algunos rasgos de la cerámica y la arquitectura, pero sin mayor trascendencia.

No obstante, Castro (1992) advierte la magnitud de esta presencia y cuán poco se conocía todavía, llamando a desarrollar muchos más estudios para tener una idea certera de la expansión incaica en dichos territorios. Al respecto, Silva (1985) ya había propuesto una intervención más directa, incluso militar, que se vinculaba al interés del imperio por la obtención de recursos minerales, energías humanas y la ganadería concentrada en Atacama. Asimismo, más tarde, Cornejo (1995) coincide con algunos de estos postulados, aunque reemplazando el militarismo por una integración en gran medida simbólica. De este modo, el Inka privilegiaría una ruta vial expansiva por sobre los $3.000 \mathrm{msm}$, que se ubicaría a lo largo del Loa en un eje norte-sur y en puntos estratégicos de sus quebradas para controlar a la población local, sus recursos minerales y el paso hacia el sur, desplegando sus actos políticos en el contexto de la sacralidad local, sin mayor interés por el ámbito doméstico de sus poblaciones. Profundizando en este punto, Gallardo y colaboradores (1995) perciben una actitud muy elaborada del Inka, la que incluso es coincidente con estrategias propiamente cuzqueñas, donde la arquitectura se vuelve la mejor expresión simbólica de dominación a través de actos de fundación y refundación.

Por lo tanto, con los avances logrados por estos estudios fue cambiando la perspectiva que se tenía del Inka en Atacama, obligando a una mayor sistematización de muchas más evidencias y de síntesis interpretativas novedosas, al mismo tiempo que más sustantivas (Aldunate 1991). A fines de 1990 y a partir de la variada evidencia material incaica detectada en la localidad de Caspana (río Salado, afluente del Loa), se llevó a cabo un estudio que abordó el fenómeno político representado por el Tawantinsuyo en la región (Adán y Uribe 2004). Este trabajo dio cuenta que el interés imperial por el territorio fue mayor que el pensado hasta esos momentos, permitiendo hipotetizar una pre- 
sencia directa del Estado, a través del manejo de los ancestrales principios andinos de organización socioeconómica. Así, la reciprocidad y redistribución fueron convertidas en mecanismos de apropiación y dominio a través del potencial simbólico de una materialidad arqueológicamente perceptible (Uribe et al. 1998). En este sentido, se postuló que las oposiciones manifiestas por la materialidad de inkas y grupos locales (arquitectura, cerámica, arte rupestre, vialidad y funebria, entre otros), podían expresar el manejo del Inka sobre las contradicciones sociales internas y su aprovechamiento de la producción agroganadera excedentaria, las relaciones multiétnicas de complementariedad, el intercambio y los cultos religiosos en favor de la presencia estatal en la región (Uribe y Adán 2004). Consecuente con lo anterior, en la actualidad el problema se aborda desde la periferia del núcleo atacameño, particularmente desde el Alto Loa y el sistema vial, para obtener una visión más penetrante de los vínculos culturales, económicos, sociales y políticos del Tawantinsuyo (Berenguer 2003).

Por consiguiente, hoy día se ha comenzado a generar una síntesis mucho más íntegra y profunda de la presencia del Inka y la incorporación del territorio y poblaciones de Atacama al Tawantinsuyo, quedando escasas dudas de que la región concentró una parte relevante de las operaciones del imperio. No obstante, todavía falta comprender los alcances más profundos de esta presencia en Atacama, por lo que en esta oportunidad nos abocamos a caracterizar con mayor detalle la situación del Inka en San Pedro de Atacama; con el especial propósito de contribuir a través de un espacio paradójicamente todavía poco conocido en este tema (Uribe 1999-2000), a un mejor acercamiento del modo en que esta fuerte presencia fue posible en el desierto más árido del mundo.

\section{EI Inka en San Pedro de Atacama}

Además de otros sitios del Loa (Adán 1999), Catarpe Este y los tambos de Licancabur y Peine, dan cuenta de la imposición de la arquitectura del Tawantinsuyo en San Pedro de Atacama durante el período Tardío (Niemeyer y Schiappacasse 1988). De estos, sin embargo, Catarpe Este (Figura 2) es paradigmático en términos de las manifestaciones de una incorporación efectiva de la región al funcionamiento imperial (Lynch y Núñez 1994). El asentamiento, si bien comparte varias característi- cas con el resto de los sitios habitacionales de la región (e.g. Turi, Catarpe Oeste, Zápar o Peine), evidencia la presencia de una importante plaza doble en una ubicación central (hacia el este), una frecuencia similar de unidades domésticas y silos o collcas, una abundancia relativa de muros dobles, etc. La arquitectura de Catarpe Este indica, por lo tanto, la existencia de abundante almacenaje, la disponibilidad de espacios habitacionales sin sepulturas y sobre todo la existencia de grandes explazos para funciones administrativas y público-ceremoniales. Su construcción se remontaría según nuestros fechados a 1.510 d.C. (Uribe y Adán 2004), e indicaría una lógica de ocupación que se aleja de la modesta dinámica comunitaria que hemos observado en los poblados locales, aunque se articuló con su estructura económica y social (Uribe et al. 2002, 2004).

Sobre estas viejas y nuevas dinámicas, la alfarería (Figura 3) indica que los tipos foráneos se incrementan aún más en estos momentos y remiten a vínculos con el altiplano, la vertiente oriental circumpuneña e incluso los valles occidentales; mientras lo incaico adquiere un carácter marcadamente trasandino (e.g. tipos Yavi y La Paya), lo cual redundaría en la transformación de la cerámica local (Uribe 1999; Uribe y Carrasco 1999). A través de esta alfarería, además, se aprecia una integración diferenciada de los asentamientos locales al orden estatal, extendiéndose su ocupación hasta épocas coloniales en algunos de ellos.

$\mathrm{Al}$ respecto, los asentamientos inferidos a partir del análisis funcional de su alfarería y construcciones indican que todos los sitios inmediatamente preincaicos (e.g. Catarpe, Quítor, Zápar y Peine) tendrían un carácter eminentemente doméstico, con recintos habitacionales donde se preparan, sirven y almacenan alimentos. También ocurren actividades ceremoniales, coherentes con la inclusión de prácticas religiosas y funerarias manifiestas en la arquitectura que se incorpora dentro, junto o cerca de ellos (e.g. chullpas), pero las cuales difieren tanto en escala como intensidad, realizándose de manera independiente en unos y otros. Tal situación, sugiere una dinámica de comunidad o "aillo" para las sociedades que habitaron estos poblados que los convierte en unidades autónomas, sin distinguirse uno o unos pocos núcleos como antes (Uribe et al. 2004).

Con el Inka, en tanto, el desarrollo de una organización jerarquizada, la generación de exceden- 


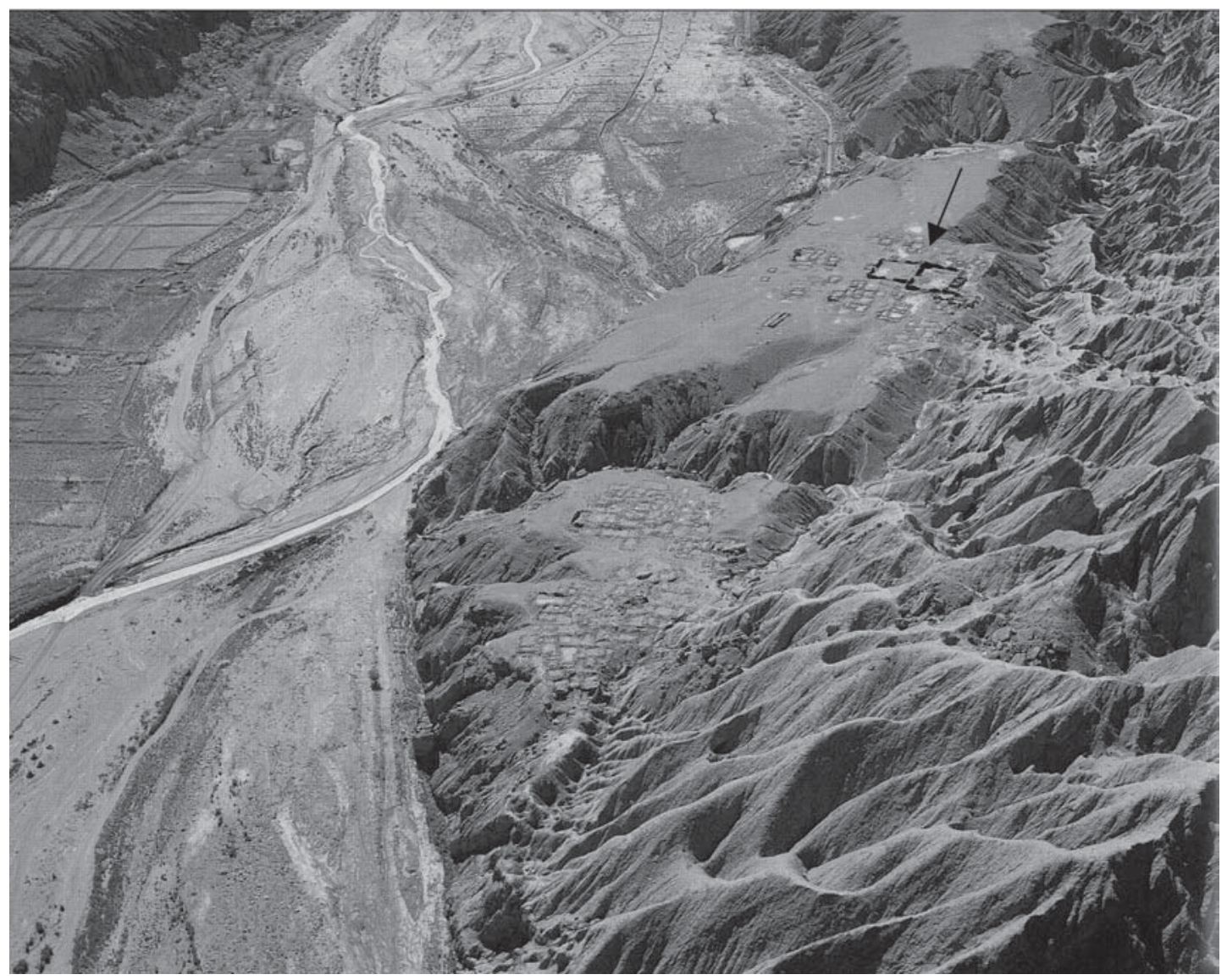

Figura 2. Vista aérea del sitio Catarpe Este. Parte superior la plaza o cancha doble (con flecha); parte inferior poblado local Catarpe Oeste (gentileza de Fernando Maldonado).

Aereal view of Catarpe East. Upper section square or cancha (arrow); lower section Catarpe West local town (courtesy of Fernando Maldonado).

tes económicos y el rol de los líderes en actividades redistributivas parecen tener un papel aún más protagónico al interior de los grupos de San Pedro de Atacama; muy ligado a la competencia preexistente sobre recursos de agua, tierra y los contactos a larga distancia por complementariedad de recursos (Uribe et al. 2002). Así, desde fines del Intermedio Tardío los materiales líticos enfatizan la molienda, tanto agrícola como con otros fines (e.g. ceremoniales o minería), desplegando una gran diversidad morfológica y polifuncionalidad de los artefactos. Sin embargo, desde el Tardío también es claro apreciar que junto con lo funcional, los artefactos líticos y la piedra en general adquieren un carácter más versátil y simbólico que se expresa en la challa de minerales en tumbas, chullpas y caminos. Se configura, de este modo, una conducta común para el área, en conjunto con el río Loa
(Uribe y Carrasco 1999), dentro de la cual también resulta importante la producción de cuentas de malaquita y calcedonia, aparte de las de concha. Esto es coherente con la concentración de chullpas y sepulturas al interior de los poblados o en la presencia de canchas y collcas en las instalaciones incaicas, y también coincide con la funcionalidad cerámica, el almacenamiento y la actividad ceremonial que van en aumento con el Inka (Uribe et al. 2002). El material lítico, en suma, confirma la necesidad de procesar y acopiar ciertos alimentos, los que seguramente se emplean en las festividades comunales, en conjunto con una minería de recursos simbólicos destinados al intercambio (Núñez 1999).

Además, comparando sitios preincaicos y contemporáneos al Tawantinsuyo, en todos se observa que el manejo de fauna se mantiene uni- 


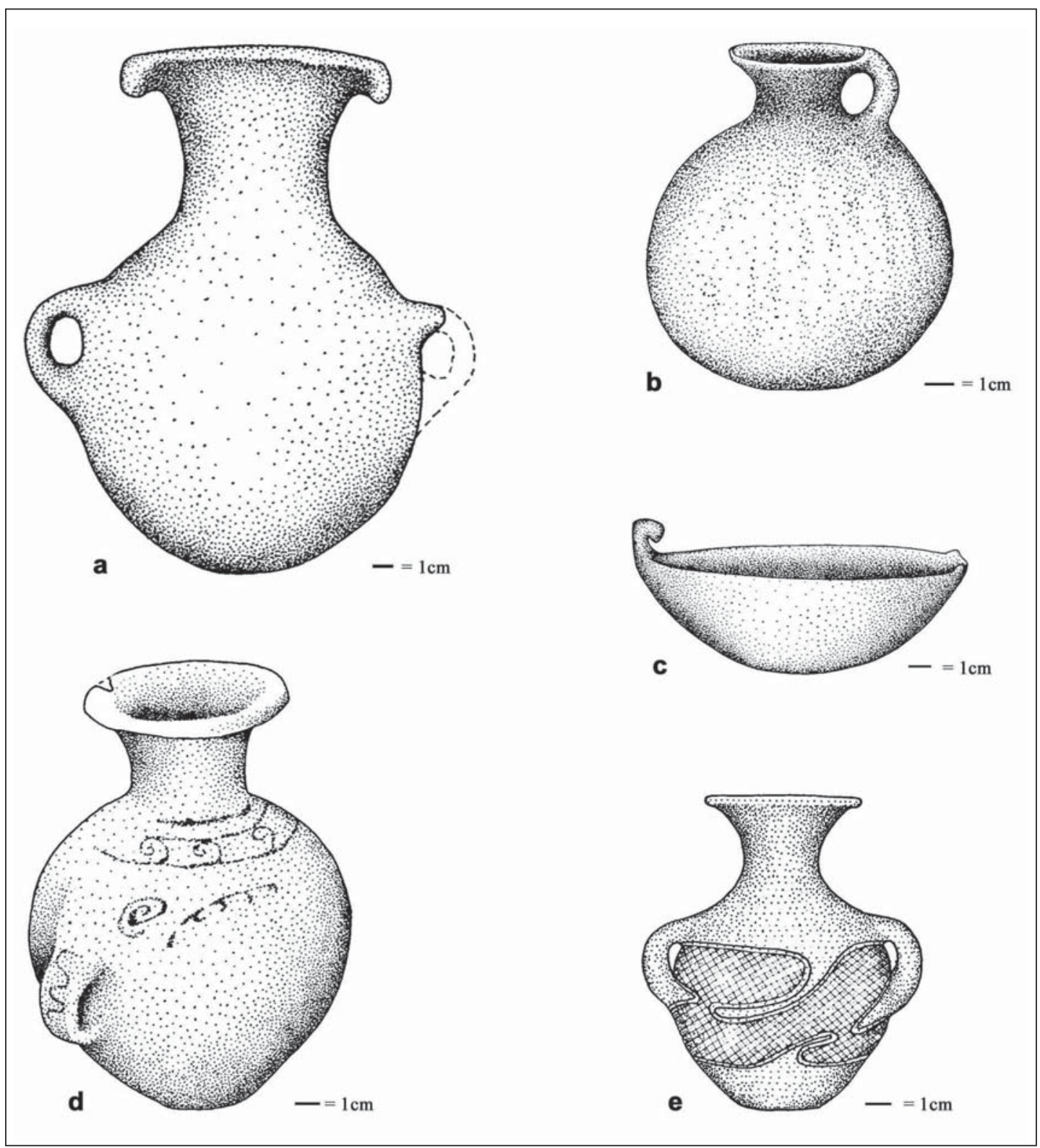

Figura 3. Componente cerámico incaico local y foráneo: (a) Tipo Lasana café rojizo revestido pulido, (b) Tipo Turi rojo revestido exterior-negro alisado interior, (c) Turi rojo revestido pulido ambas caras, (d) y (e) Tipos Yavi-La Paya.

Pottery of local and foreign origin: (a) Type Lasana redish brown slip, (b) Type Turi red slip with black inner surface, (c) Type Turi red polished slip both faces, (d) and (e) Types Yavi- La Paya.

forme, mientras que el material vegetal adquiere un notorio aumento en los poblados más tardíos (Catarpe, Quítor, Zápar y Peine). Lo anterior sugiere una transformación del ancestral sistema ganadero y caravanero de la región (Núñez 1992), el cual ahora estaría apoyado en una producción agrícola mayor, más estable y de gran escala, ca- paz de sustentar una cantidad de población más grande y segmentada (Adán y Uribe 1995). Con relación al intercambio y las caravanas, hallazgos textiles de Peine, que se vinculan con la textilería local previa (e.g. gorros tipo corona y bolsas), presentan técnicas, decoración y colores que insertan a las bolsas dentro de un estilo tardío 
compartido con el Loa y Noroeste Argentino (Agüero 2000). Al mismo tiempo, muestran una gran estandarización los colores y decoración, en cierto sentido parecida a los tejidos de estatuillas y santuarios de altura incaicos (Figura 4), por lo que con gran certeza pueden ser atribuidos al Inka. Esto, sin embargo, no significa una simple adscripción a los patrones cuzqueños, porque estilísticamente no es así, sino más bien se trataría de la intervención de la industria local por el Tawantinsuyo. Esta intervención implicaría una reorganización de la producción textil vinculada al intercambio, denotando un tráfico distinto y controlado por el Estado; perfilando una manufactura de bolsas casi en serie para un movimiento de recuas de mayor escala basado en el nexo entre Atacama y el Noroeste Argentino, ya anunciado por el marcado aspecto transandino de la cerámica Inka foránea.

Todo esto confirma y es consistente con las particularidades que adquieren los asentamientos, la alfarería y restos líticos relacionados con la nueva realidad demográfica y económico-social, comprendida por unidades independientes, aunque relacionadas y luego jerarquizadas en torno a centros como Catarpe Este.

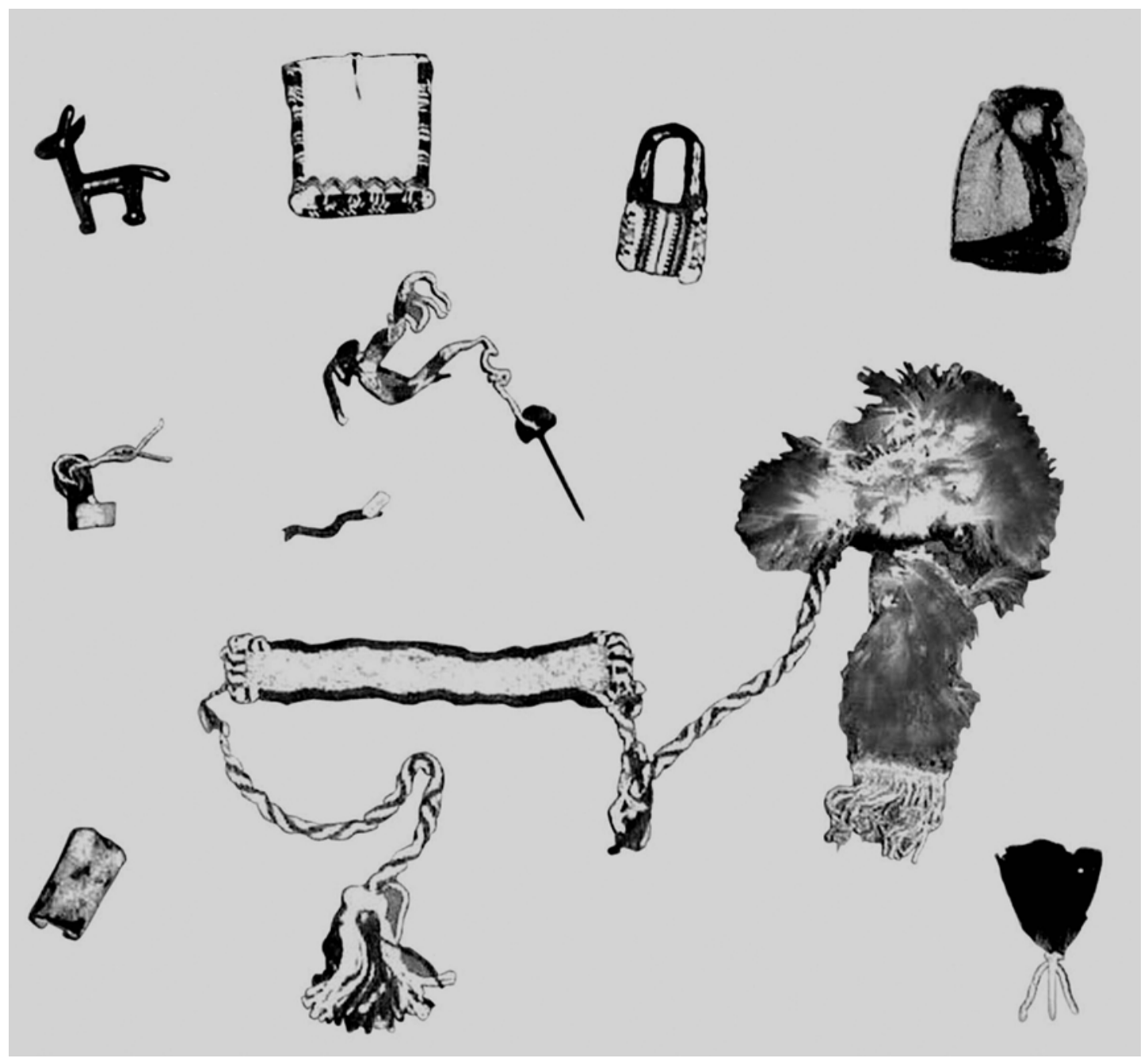

Figura 4. Textilería y metalurgia incaica del santuario de altura del cerro Pili, San Pedro de Atacama (gentileza Museo Arqueológico R. P. Gustavo Le Paige).

Textile and metal objects from the highland Inca sanctuary cerro Pili, San Pedro de Atacama (courtesy of Museo Arqueológico R. P. Gustavo Le Paige). 
Según esto, el manejo de los líderes locales debió ser clave para la articulación de la producción comunitaria con la estructura política unitaria que logra el imperio. Al respecto, tabletas y calabazas pirograbadas procedentes del espacio funerario remiten a elementos novedosos (Ayala et al. 1999; Uribe et al. 2002), especialmente compartidos con el Noroeste Argentino y el altiplano de Bolivia, volviéndose predominantes los del noroeste. Por una parte, estos materiales de gran relevancia simbólica demuestran una amplia interacción circumpuneña que podría extenderse incluso hasta Tarapacá. Por otra, refieren a una importante complejidad social y política que debió desenvolverse por situaciones de complementariedad, involucrando diversas negociaciones entre las autoridades que dirigían empresas de intercambio y una ardua competencia por el mejor posicionamiento de sus comunidades. Por lo mismo, las concepciones acerca del poder habrían cambiado como parece expresarse en las nuevas manifestaciones iconográficas, donde destacan las figuras humanas por sobre las imágenes de seres sobrenaturales que antes portaban estos objetos, particularmente las tabletas que se asociaban a un orden social más chamánico que el de ahora (Llagostera 1996; Uribe et al. 2002).

En suma, esta complejidad "atacameña" del período Tardío debió integrar el impulso demostrado por el desarrollo de la producción agrícola y caravanera experimentado previamente en toda la región (Núñez 1992; Schiappacasse et al. 1989; Uribe et al. 2002), lo que el Inka supo anexar para su propio provecho promoviendo la dinámica "supra" comunitaria, el papel de sus autoridades y las distintas complementariedades como ocurre con el Noroeste Argentino.

\section{Ideología, Inkas y Atacama}

Con el objetivo de precisar esta capacidad del Tawantinsuyo para producir la integración que observamos en Atacama, explícita en San Pedro y el Loa, nos parece necesario arrimarnos a otras reflexiones compartidas con el mundo andino que nos permite concluir mejor nuestro trabajo y no quedarnos en la mera explicación económica y funcional.

Recordando a Murra (1972 y 1983), vemos que su interés en la investigación de los Andes siempre estuvo enfocado en lo económico, pero su atracción también se centró en el aspecto político de este énfasis (Henderson y Netherly 1993). De hecho, el enfoque económico de Murra es una cuestión más práctica que un principio, en particular porque las fuentes documentales europeas generalmente adoptaron una perspectiva económica y administrativa de las sociedades andinas. Pero, en términos pragmáticos, la realidad cultural de los Andes siempre dirige la atención sobre los grupos sociales y no sólo a la tenencia de la tierra o la riqueza.

Compartimos, entonces, que en los Andes lo cognitivo e ideológico está explícitamente incorporado en las esferas económicas y sociales, donde la actividad ritual tiene implicancias económicas y lo ceremonial se articula con lo material (Henderson y Netherly 1993). Morris (1993), en esta línea, discute el tema de la expansión incaica a través de los sistemas de reciprocidad, la producción y el intercambio, manejando justamente un concepto más sustantivo de la economía andina. Para el autor, el proceso expansivo se encuentra íntimamente asociado a la emergencia de nuevas clases de bienes u objetos, cuya función primordial fue comunicar información sobre la sociedad y sus relaciones de origen y clase, ya que por medio del control y la manipulación de tales bienes tomaron lugar los cambios sociopolíticos como la generación de riqueza y, por supuesto, el incremento de poder.

Pero, bajo dicho marco, también se agrega el tema de las relaciones cara a cara entre distintas clases de individuos o grupos, puesto que de ambas situaciones dependerían las obligaciones de trabajo de los conquistados y su manipulación por el Estado, produciendo bienes para usarlos como regalos a los líderes y proveyendo bebida y comida a los trabajadores (Morris 1993). De ahí que se generarían situaciones, escenarios y asentamientos especiales para esta actividad mediante un ceremonialismo donde se pretende dar la idea de "generosidad" del gobernante dentro de un ambiente festivo, en el cual los objetos adquieren gran eficacia simbólica en tanto poder. Lo anterior debió redundar en una reorganización del trabajo y del ciclo productivo, generando una disciplinada calendarización de grandes festividades con enorme despliegue simbólico donde se expresaba la gran generosidad del Inka. La idea, según Morris, era darle mayor valor al trabajo invertido, desplegando roles, estatus e identidades nuevas, manejando cuestiones de tipo cognitivas y emocionales 
con relación a una sociedad y solidaridad casi "patriótica". El imperio, por lo tanto, invertiría en una especie de dramatización colectiva de carácter "nacional", manifiesta en la enorme movilización de la fuerza de trabajo y gran propaganda estatal en fiestas, generando la hermandad entre sus miembros. En consecuencia, el espacio público se convierte en el lugar privilegiado de la jerarquía social y sus distintas partes constituyentes. Este sería el caso de Huanuco Pampa, estudiado por Morris y Thompson (1985).

Hyslop (1993), por su parte, también reflexiona acerca de las variaciones y variabilidad de los restos materiales incaicos, porque, según su criterio, esto ayuda a comprender a los inkas como también a la gente que ellos gobernaron. Por ejemplo, su arquitectura y cerámica, pero observando que esas materialidades no son siempre idénticas con el Cuzco, sino más bien parecidas y diferentes al mismo tiempo. Así, en la arquitectura como la cerámica se replicaron las formas más que su perfección o las decoraciones, a pesar de ser mensajes más directos y particulares de la presencia estatal. En general, lo anterior ha sido considerado una expresión de marginalidad; sin embargo, la ausencia de fina sillería en la arquitectura, cerámica de imitación imperfecta o la misma falta de grandes centros no resulta ser contradictoria con la conquista e incorporación al imperio. Al contrario, se trataría de construcciones sociales particulares donde se involucraron conceptos distintos, pero significativos para ambas partes y que implicaban una especial representación del mundo, en cuya construcción participarían conquistadores y conquistados. Por lo tanto, para comprender lo incaico fuera del Cuzco, Hyslop (1993) plantea como necesario reconocer que las poblaciones locales no sólo hicieron el trabajo y que los inkas tampoco se restringieron únicamente a ordenar y manejar estas obras.

Por lo tanto, asumiendo desde la arqueología postprocesual una relación más activa de las partes involucradas socialmente, una mayor importancia dada a las ideas de mundo o sus representaciones en conjunto y las evidencias materiales presentes en San Pedro de Atacama como del resto de la región y los Andes (Uribe et al. 2002), nos planteamos frente al posible modo de operar de esta integración entre inkas y locales. Lo cual, obviamente, nos parece que tuvo un carácter o naturaleza esencialmente ideológica; pero no como simple efecto religioso, sino con causas y consecuencias sociales concretas dentro de la realidad local. En su expansión, por lo tanto, el Tawantinsuyo habría impulsado el desarrollo de las fuerzas productivas a través de una fuerza de trabajo numerosa previa, apoyada en el crecimiento demográfico local y de sus medios de producción, sobre todo, agrícolas y el intercambio, cuya mayor fuerza de trabajo requirió de una organización social más compleja. Las poblaciones locales de Atacama, entonces, desarrollaron aún más sus fuerzas productivas y potenciaron la generación de excedentes impulsando una jerarquía social que conllevaba a un sistema políticamente cada vez menos igualitario (Uribe y Adán 2004).

De este modo, tal cual apreciamos en Catarpe Este, con el Inka son más claros los espacios públicos como expresión del aparato administrativo, demostrando el control a través del cual se dirige la fuerza de trabajo hacia la producción estatal; distinguiéndose un grupo productor de bienes y alimentos, de otro especializado en las actividades políticas, ideológicas y administrativas que se expone en los contextos funerarios (e.g. Hostería de San Pedro), presentes en el salar (Ayala et al. 1999). El Tawantinsuyo, por lo tanto, se apropia de la fuerza de trabajo y la producción de las unidades domésticas como un excedente que es manejado por los segmentos ya diferenciados de la población local, que ahora se convierten en administradores, incluso políticos e ideológicos. Pero, para que esto tuviera un real sentido y una respuesta positiva por parte del resto de la población y las elites pudieran actuar a favor del Estado, se debió generar un amplio control de la conciencia social a través de la participación ideológica en la formación económica y social del imperio.

De esta manera, la expresión arqueológica que llamamos "inka local" representaría esa coherencia y el dominio. Ello por medio de referentes sociales significativos como las fiestas redistributivas para las comunidades dirigidas por los jefes locales, lo que jugó un papel crucial como lo evidencia la importante producción de contenedores de líquidos de apariencia incaica, claros espacios de preparación y consumo público de alimentos, así como almacenamiento a gran escala que, si bien se venían dando de antes y sin perder su identidad (Uribe y Carrasco 1999), se transformaron de acuerdo a la trama social, religiosa y estética que reproducía el sistema incaico. En suma, no sólo la idea 
de generosidad que representaba al Inka (Martínez 1995), sino también las de "participación, solidaridad o hermandad" que muchas veces evocan la ambigüedad de los restos arqueológicos del período como ocurre en Atacama, parecieran definir la forma en que operó la cohesión del Estado a nivel de las bases. De tal modo que estas también debieron sentirse parte del orden impuesto por el Tawantinsuyo, donde no sólo el Inka era la única y fundamental pieza del cosmos andino.
Agradecimientos: Al Fondo Nacional de Ciencia y Tecnología (Proyecto FONDECYT 1000148), al Instituto y Museo R. P. Gustavo Le Paige s. j. y a las comunidades indígenas de San Pedro de Atacama. Esto mismo tampoco habría sido posible sin la colaboración de distintas personas que participaron de la investigación, especialmente representadas por mis colegas y amigas Leonor Adán y Carolina Agüero. Asimismo, a Paulina Chávez por sus ilustraciones.

\section{Referencias Citadas}

Adán, L.

1999 Aquellos antiguos edificios. Acercamiento arqueológico a la arquitectura prehispánica Tardía de Caspana. Estudios Atacameños 18:13-33.

Adán, L. y M. Uribe

1995 Cambios en el uso del espacio en los períodos agroalfareros: un ejemplo en ecozona de quebradas altas, la localidad de Caspana. Actas del II Congreso Chileno de Antropología Tomo II: 541-555. Colegio de Antropólogos de Chile, Valdivia.

2004 El Inka en la localidad de Caspana: un acercamiento al pensamiento político andino (río Loa, Norte de Chile). Estudios Atacameños, en prensa.

Agüero, C.

2000 Fragmentos para armar un territorio. La textilería en Atacama durante los períodos Intermedio Tardío y Tardío. Estudios Atacameños 20:7-28.

Aldunate, $\mathrm{C}$.

1991 Arqueología en el Pukara de Turi. Actas del XIII Congreso Nacional de Arqueología Chilena Tomo 2: 61-78. Boletín del Museo Regional de la Araucanía 4, Temuco.

Ayala, P., O. Reyes y M. Uribe

1999 El cementerio de los Abuelos de Caspana: el espacio mortuorio local durante el dominio del Tawantinsuyu. Estudios Atacameños 18:35-54.

Berenguer, J.

2003 El Inkañam en el Alto Loa, II Región de Chile: caminos, hitos y asentamientos. Ponencia presentada en el $51^{\circ}$ Congreso Internacional de Americanistas, Santiago.

Castro, V.

1992 Nuevos registros de la presencia Inka en la Provincia de El Loa, Chile. Gaceta Arqueológica Andina 21(VI): 139-154.

Cornejo, L.

1995 El Inka en la región del río Loa: lo local y lo foráneo. Actas del XIII Congreso Nacional de Arqueología Chilena Tomo 1:203-213. Hombre y Desierto 9, Antofagasta.

Dauelsberg, P.

1959 Cerámica del Valle de Azapa. Boletín del Museo Regional de Arica 3:47-51.

Foucault, M.

2002 Vigilar y Castigar: el Nacimiento de la Prisión. Traducido por A. Garzón del Camino. Siglo Veintiuno Editores, Buenos Aires.
Gallardo, F.

2004 El arte rupestre como ideología: un ensayo acerca de pinturas y grabados en la localidad del río Salado (desierto de Atacama, Norte de Chile). En Actas del XV Congreso Nacional de Arqueología Chilena, Chungara Revista de Antropología Chilena Número Especial: 427-440.

Gallardo, F., M. Uribe y P. Ayala

1995 Arquitectura Inka y poder en el pukara de Turi. Gaceta Arqueológica Andina 24 (VII): 151-172.

Henderson, J. y P. Netherly

1993 Murra, materialism, anthropology, and the Andes. En Configurations of Power Holistic Anthropology in Theory and Practice, editado por J. Henderson y P. Netherly, pp. 1-8. Cornell University Press, Ithaca y Londres.

Hodder, I.

1994 Interpretación en Arqueología. Corrientes Actuales. Edición ampliada y puesta al día. Traducido por M. J. Aubet y J. A. Barceló. Crítica, Barcelona.

Hyslop, J.

1993 Factors influencing the transmission and distribution of Inka cultural materials throughout Tawantinsuyo. Latin Americans Horizons: a Symposium at Dumbarton Oaks, editado por D. Rice, pp. 337-356. Dumbarton Oaks, Washington, D.C.

Latcham, R.

1938 Prehistoria de la Región Atacameña. Prensas de la Universidad de Chile, Santiago.

Leone, $\mathrm{M}$.

1986 Symbolic, structural and critical archaeology. American archaeology. Past and Future: a Celebration of the Society for American Archaeology 1935-1985, editado por E. Meltzer et al., pp. 415-437. Smithsonian Institution Press, Washington D.C.

Lynch, T. y L. Núñez

1994 Nuevas evidencias Inkas entre Kollahuasi y Río Frío (I y II Regiones de Chile). Estudios Atacameños 11:145-164.

Llagostera, A.

1976 Hipótesis sobre la expansión incaica en la vertiente occidental de los Andes Meridionales. En Homenaje al R. P. Gustavo Le Paige s. j., editado por H. Niemeyer, pp. 203-218. Universidad del Norte, Antofagasta.

1996 San Pedro de Atacama: nodo de complementariedad reticular. En Integración Surandina: Cinco Siglos Después, editado por X. Albó et al., pp. 17-41. Centro de Es- 
tudios Regionales Andinos Bartolomé de las Casas, Corporación Norte Grande, Taller de Estudios Andinos, Universidad Católica del Norte, Cuzco-Antofagasta.

Martínez, J. L.

1995 Autoridades en los Andes, los Atributos del Señor. Pontificia Universidad Católica del Perú, Fondo Editorial, Lima.

Morris, C.

1993 The wealth of a native American state: value, investment, and mobilization and the Inka economy. En Configurations of Power Holistic Anthropology in Theory and practice, editado por J. Henderson y P. Netherly, pp. 36-50. Cornell University Press, Ithaca y Londres.

Morris, C. y D. Thompson

1985 Ниаписо Paтpa. Thames and Hudson, Londres.

Mostny, G.

1949 Ciudades atacameñas. Boletín del Museo Nacional de Historia Natural 24:125-212.

Munizaga, C.

1957 Secuencias culturales de la zona de Arica. En Arqueología Chilena, editado por R. Schaedel, pp. 79-123. Universidad de Chile, Santiago.

Murra, J.

1972 El "control vertical" de un máximo de pisos ecológicos en la economía de las sociedades andinas. En Visita a la Provincia de León de Huanuco en 1562, Iñigo Ortiz de Zúñiga, editado por J. Murra, pp. 429-472. Universidad Emilio Valdizán, Huanuco.

1983 La Organización Económica del Estado Inca. Editorial Siglo XXI, México D.F.

Niemeyer, H. y V. Schiappacasse

1988 Patrones de asentamiento incaicos en el Norte Grande de Chile. En La Frontera del Estado Inca, editado por T. Dillehay y P. Netherly, pp. 141-179. BAR International Series 442, Oxford.

Núñez, L.

1992 Cultura y Conflicto en los Oasis de San Pedro de Atacama. Editorial Universitaria, Santiago.

1999 Valoración minero-metalúrgica circumpuneña: menas y mineros para el Inka rey. Estudios Atacameños 18:177-221

Núnez, L. y T. Dillehay

1995 Movilidad Giratoria, Armonía Social y Desarrollo en los Andes Meridionales: Patrones de Tráfico e Interacción Económica. Universidad Católica del Norte, Antofagasta. Núñez, P.

1991 Posibilidades agrícolas y población del incario en el área atacameña. Norte de Chile. Actas del XII Congreso
Nacional de Arqueología Chilena Tomo I: 259-268. Boletín del Museo Regional de La Araucanía 4, Temuco.

Pärssinen, M. y A. Siiriäinnen

1997 Inka-style ceramics and their chronological relationship to the Inka expansion in the southern lake Titicaca area (Bolivia). Latin American Antiquity 8: 255-271.

Raffino, R.

1981 Los Inkas del Kollasuyu. Ramos Americana Editores, La Plata, Buenos Aires.

Schiappacasse, V., V. Castro y H. Niemeyer

1989 Los desarrollos regionales en el Norte Grande. En Culturas de Chile. Prehistoria, editado por J. Hidalgo, V. Schiappacasse, H. Niemeyer, C. Aldunate e I. Solimano, pp. 181220. Editorial Andrés Bello, Santiago.

Silva, O.

1985 La expansión Incaica en Chile: problemas y reflexiones. Actas del IX Congreso Nacional de Arqueología Chilena, pp. 321-340. Museo Arqueológico de La Serena, La Serena.

Uribe, $\mathrm{M}$.

1999 La alfarería Inca de Caspana. Boletín de la Sociedad Chilena de Arqueología 27:11-19.

1999-2000 La arqueología del Inka en Chile. Revista Chilena de Antropología 15:63-97.

Uribe, M. y L. Adán

2004 Acerca del dominio Inka, sin miedo, sin vergüenza. Actas del XV Congreso Nacional de Arqueología Chilena, Arica. Chungara Revista de Antropología Chilena Volumen Especial: 467-480.

Uribe, M. y C. Carrasco

1999 Tiestos y piedras talladas: La producción cerámica y lítica en el período Tardío del Loa Superior. Estudios Atacameños 18:55-72.

Uribe, M., L. Adán y C. Agüero

2002 El dominio del Inka, identidad local y complejidad social en las tierras altas del desierto de Atacama, Norte Grande de Chile (1450-1541 d.C.). Boletín de Arqueología PUCP: 301-336.

2004 Arqueología de los períodos Intermedio Tardío y Tardío de San Pedro de Atacama y su relación con la cuenca del Loa. Actas del XV Congreso Nacional de Arqueología Chilena, Arica. Chungara Revista de Antropología Chilena Volumen Especial: 943-956.

Uribe, M., V. Manríquez y L. Adán

1998 El poder del Inka en Chile: aproximaciones a partir de la arqueología de Caspana (río Loa, Desierto de Atacama). Actas del Tercer Congreso Chileno de Antropología Tomo II: 706-722. Colegio de Antropólogos de Chile, Temuco. 